\title{
CASE REPORT \\ Tetrafid mandibular condyle: a unique case report and review of the literature
}

\author{
H Şahman*,1, OA Etöz ${ }^{2}$, AE Şekerci $^{1}$, M Etöz ${ }^{1}$ and Y Şişman ${ }^{1}$ \\ ${ }^{1}$ Department of Oral Diagnosis and Radiology, School of Dentistry, Erciyes University, Kayseri, Turkey; ${ }^{2}$ Department of Oral and \\ Maxillofacial Surgery, School of Dentistry, Erciyes University, Kayseri, Turkey
}

\begin{abstract}
Morphological changes such as bifid and trifid mandibular condyle are rare entities. The aim of the present report is to describe a unique morphological variation of the mandibular condyle which has four separate condylar heads (tetrafid mandibular condyle) and to discuss clinical and radiological differential diagnosis of tetrafid mandibular condyle with advanced imaging techniques.
\end{abstract}

Dentomaxillofacial Radiology (2011) 40, 524-530. doi: 10.1259/dmfr/62082661

Keywords: tetrafid mandibular condyle; condylar variation; three-dimensional computerized tomography; magnetic resonance imaging

\section{Introduction}

Duplication of the mandibular condyle such as bifid and trifid mandibular condyle is an uncommon variation. ${ }^{1}$ However, these conditions are increasingly being detected in view of the advanced imaging techniques, especially $\mathrm{CT}$, cone beam CT (CBCT) and MRI. ${ }^{2-5}$

Bifid or trifid mandibular condyle is usually diagnosed as an incidental finding during routine radiographic examinations and typically has no distinct clinical symptoms. ${ }^{6}$ Although the exact aetiology is unknown, some circumstances such as trauma, teratogenic drug use, genetic tendency, infection and exposure to radiation may be responsible for these variations. ${ }^{7} \mathrm{~A}$ review of the literature revealed 110 cases of bifid condyles and 4 cases of trifid condyles (PubMed database). ${ }^{1-48}$

This study presents a crown shaped and hypoplastic mandibular condyle which has four condylar heads. We describe this unique variation as "tetrafid mandibular condyle" owing to its radiographic features.

*Correspondence to: Dr Halil Şahman, Research Assistant, Department of Oral Diagnosis and Radiology, Faculty of Dentistry, Erciyes University, 38039, Kayseri, Turkey; E-mail: dt.sahman@gmail.com

Received 22 March 2010; revised 15 June 2010; accepted 6 July 2010

\section{Case Report}

A 43-year-old otherwise healthy woman was referred to our clinic with a complaint of missing teeth and caries. Panoramic radiograph and lateral temporomandibular joints (TMJs) projections of the patient revealed a curious right mandibular condyle (Figures 1 and 2). The condylar neck of the right TMJ was relatively undetectable as the length from the upper portion of the condylar head to the mandibular notch was too short. The TMJs were asymptomatic and there was no history of any previous trauma or fracture of the mandible. There were no joint sounds, pain, trismus and previous bony disease evident on clinical examination. She was born via uncomplicated vaginal delivery. A clinical examination revealed a maximum jaw opening of $44 \mathrm{~mm}$, right and left lateral opening of $5 \mathrm{~mm}$ and $7 \mathrm{~mm}$ and protrusion of $3 \mathrm{~mm}$. Masticatory muscles of the patient were non-tender to palpation. There was a negligible deviation to the right side causing facial asymmetry, especially at the open-mouth position (Figure 3a,b). To distinguish this condylar variation from the possible diagnosis of any TMJ pathology, three-dimensional (3D) CT reconstruction was performed. CT reconstruction images showed four headed right mandibular condyle (Figures 4a,b and 5). The articular surface of the right temporal bone was normal with smooth 


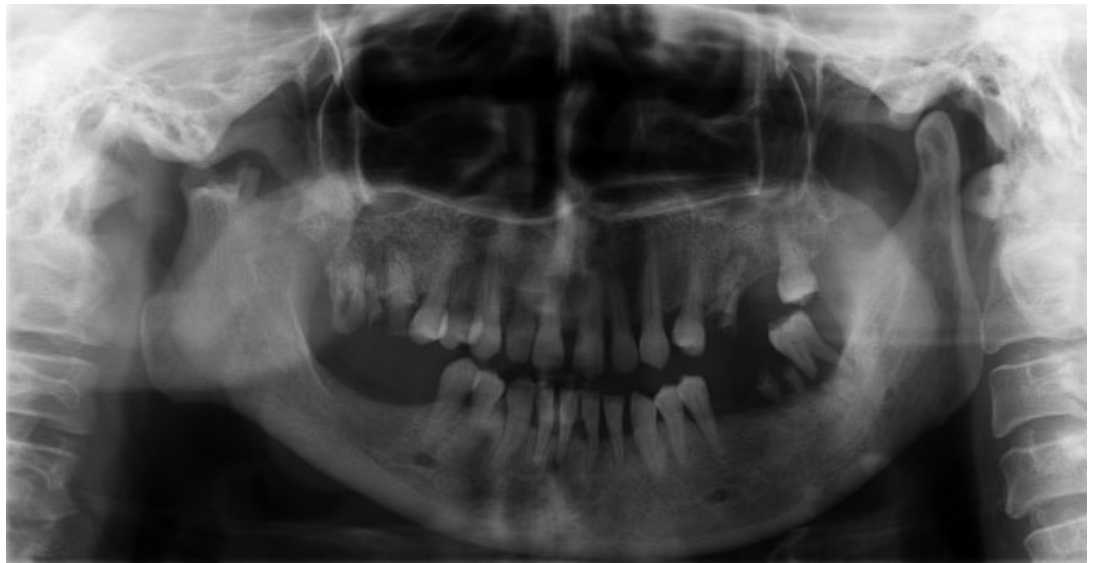

Figure 1 Panoramic radiograph showed hypoplastic and anteriorly positioned right mandibular condyle. The left mandibular condyle was normal and in the ordinary position

contours (Figure 6a,b). In order to determine the shape and position of the articular disc and surrounding soft tissues, an open-closed MRI (GE Medical Systems, Milwaukee, WI, 1.5 T magnet) was achieved (Figures 7-9). MRI findings showed that right articular disc was malformed and located in the concavity of the right mandibular condyle. Radiological findings revealed no lytic and sclerotic lesions involving either the condyles or glenoid fossa. As there were no symptoms and TMJ functions were normal, we decided to follow-up this patient.

\section{Discussion}

The terms "bifid" and "trifid" were derived from the Latin word meaning a cleft into two and three parts. In our case, there were four condylar heads on the right mandibular condyle. Hence, we chose the name of tetrafid mandibular condyle. According to our knowledge this case is a unique variation of the mandibular condyle which has not previously been shown in the literature.

In 1941, Hrdlicka ${ }^{49}$ first described bifid mandibular condyles. He found 21 samples in dried skulls in the Smithsonian Institution. 18 of those cases were unilateral and 3 were bilateral. In 1948, Schier $^{8}$ published the first clinical case in a living subject and reported one case. In 1990, Szenpetery et $\mathrm{al}^{50}$ detected 7 bifid mandibular condyles within 2077 condyles $(0.3 \%)$ in 1882 skulls. To our knowledge, only two epidemiological studies have been carried out on living subjects. In 2008, Menezes et $\mathrm{al}^{42}$ examined 50080 panoramic radiographs in a Brazilian population and found only 9 cases of bifid mandibular condyle $(0.018 \%)$. Subsequently, in 2010 , Miloglu et $\mathrm{al}^{46}$ examined 10200 panoramic radiographs in a Turkish population and reported 32 bifid mandibular condyles $(0.3 \%)$.
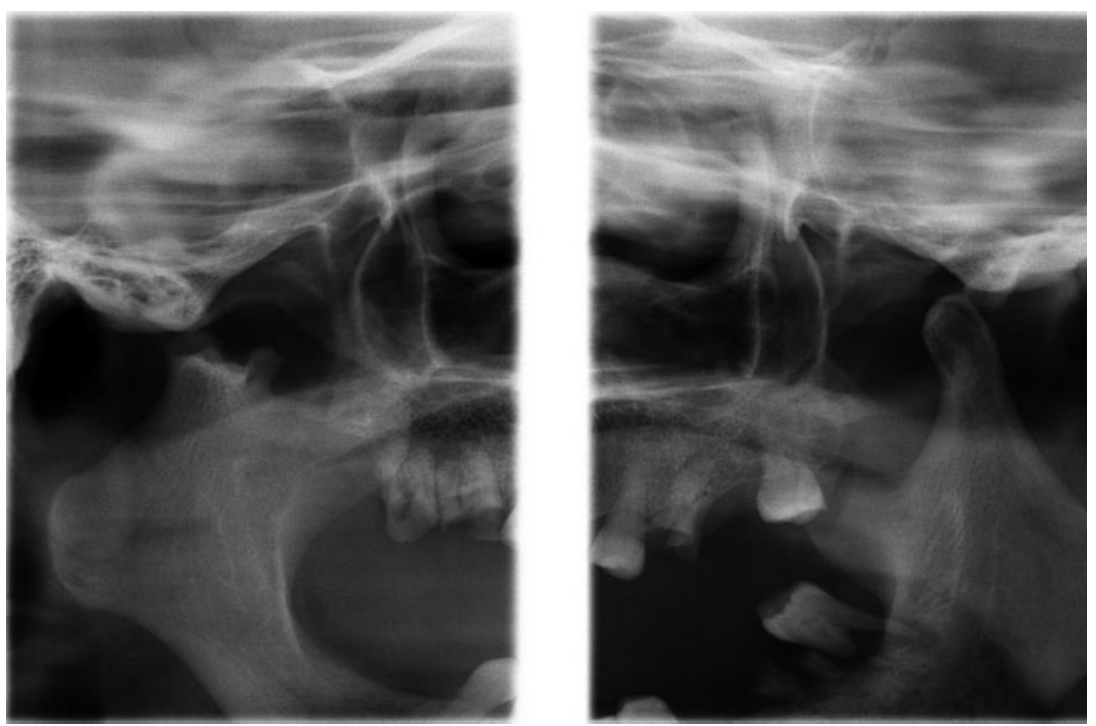

Figure 2 An open-mouth radiograph of the temporomandibular joints showed the differences between the two condyles clearly 


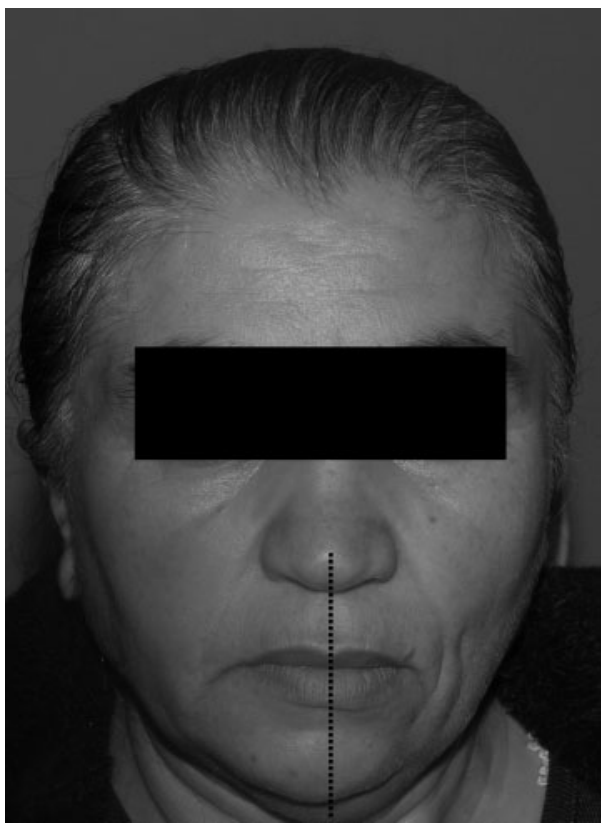

a

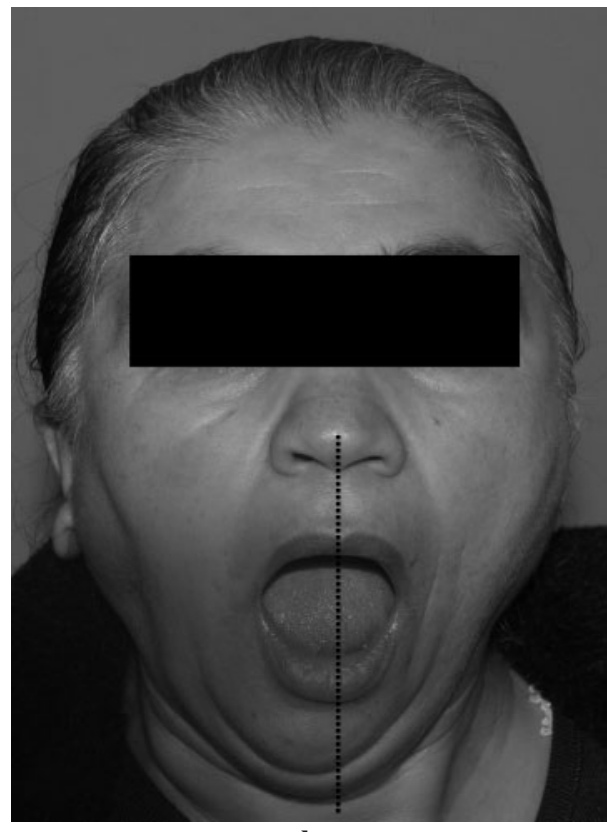

b

Figure 3 (a) Closed-mouth full-face view of the patient. (b) Open-mouth full-face view of the patient

The exact aetiology of bifid and trifid mandibular condyle is unknown. However, the most suitable theory is that it is of traumatic origin. ${ }^{15,23}$ Thomason and Yusuf $^{14}$ reported two cases of unilateral bifid mandibular condyle subsequent to condylar fracture. Antoniades et $\mathrm{al}^{23}$ also presented a case of unilateral bifid mandibular condyle which resulted following a sagittal condylar fracture. Minor trauma to the growth center of mandibular condyle may subsequently result in a variation such as bifid or trifid mandibular condyle; the deficient remodelling of the mandibular condyle may result in these condylar variations. ${ }^{3,20,23}$ In addition, teratogenic drug use, genetic tendency, infection and exposure to radiation may be responsible for these variations. ${ }^{4}$ TMJ ankylosis may also cause the formation of bifid or trifid mandibular condyle. In a retrospective study, Rehman et al ${ }^{45}$ reported 10 cases of bifid mandibular condyle in 37 patients with TMJ ankylosis. Of those ten cases, nine were post traumatic and one was post infectious. Gulati et al ${ }^{44}$ reported two cases of bifid mandibular condyle with joint ankylosis. One of them was developmental and the other was secondary to trauma. Although the most common possible aetiology has been considered as trauma, comparative studies showed that the majority of patients had no history of previous trauma or TMJ complaints. ${ }^{21,31,46}$

We found only four cases of trifid mandibular condyle in the literature (Artvinli and Kansu, ${ }^{30}$ Antoniades et $a 1,{ }^{31}$ Cagirankaya and Hatipoğlu, ${ }^{47}$ Sezgin and

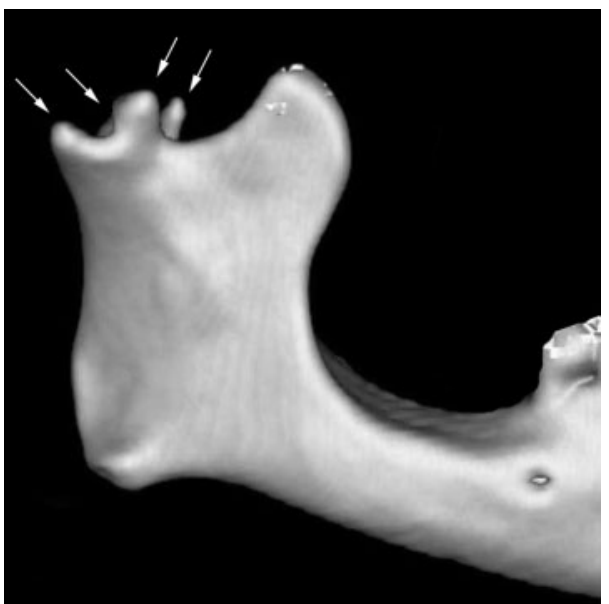

a

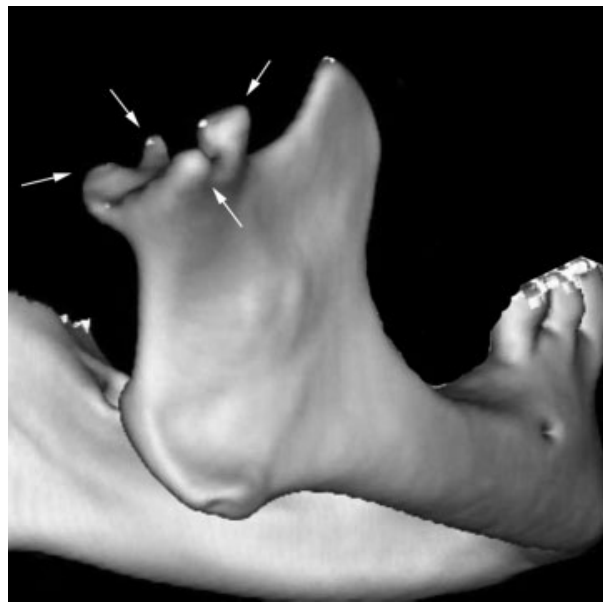

b

Figure 4 CT reconstruction images showed four heads of the right mandibular condyle (arrows) 


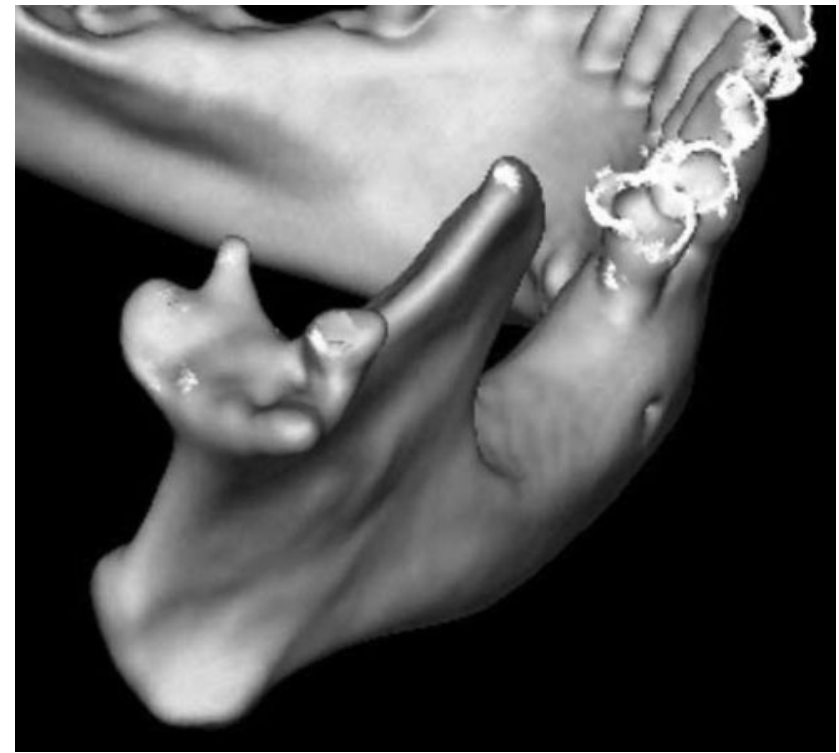

Figure 5 CT reconstruction images showed the crown-shaped condyle and concavity between the condylar heads

Kayipmaz $^{48}$ ). Three of the four reported cases of trifid mandibular condyle had history of trauma. In the present case, our patient had no history of any previous trauma, infection or exposure to radiation.

The prospective symptoms of bifid and trifid mandibular condyle are TMJ disorders, such as pain, TMJ sounds, restricted mandibular movement, trismus, swelling, ankylosis and facial asymmetry. ${ }^{10,11,15}$ However, there may not be any symptoms. In the present case, the patient had no symptoms except facial asymmetry and deviation during mouth opening.

Radiographic differential diagnosis of morphological anomalies of the mandibular condyle may include various conditions, such as degenerative TMJ diseases, fibrous or bony ankylosis, benign tumours and primary or metastatic malignant neoplasms. History of pain, restricted mouth opening and joint sounds, as well as radiographic evaluation of the disc/condyle relationship, should be carefully evaluated in order to differentiate an asymptomatic morphological anomaly from possible degenerative TMJ diseases. ${ }^{51,52}$ The patient in this report had no TMJ pain and dysfunction. Loss of condylar height and irregular structure of the TMJ in the panoramic image tend to be confused with possible malignant conditions. However, the patient was free of pain, swelling, sensory disturbance or lymphadenopathy in the head and neck region.

CT and MRI scans revealed intact articular surfaces with quite normal articular disc and the diagnosis was made as asymptomatic morphological mandibular condyle. MRI is considered the gold standard for TMJ imaging as it allows visualization of soft tissue and surrounding articular structures to determine the exact pathology of TMJ. ${ }^{53}$ Ramos et $\mathrm{al}^{37}$ presented MRI findings of a case which revealed the duplicity, showing mediolateraly orientated heads without disc displacement. In another case, Plevnia et $\mathrm{al}^{43}$ presented MRI

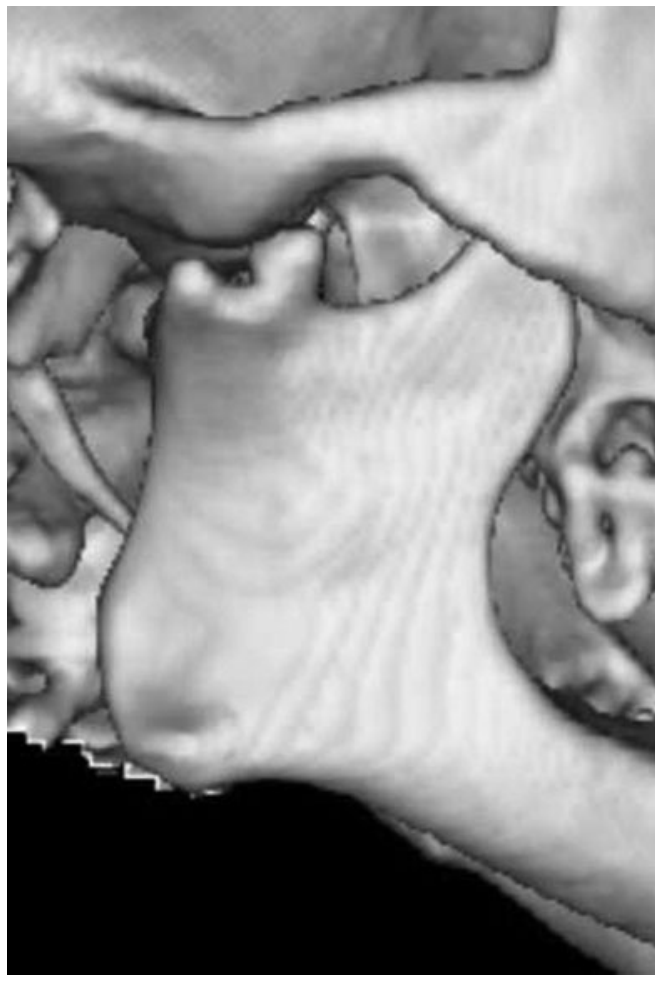

a

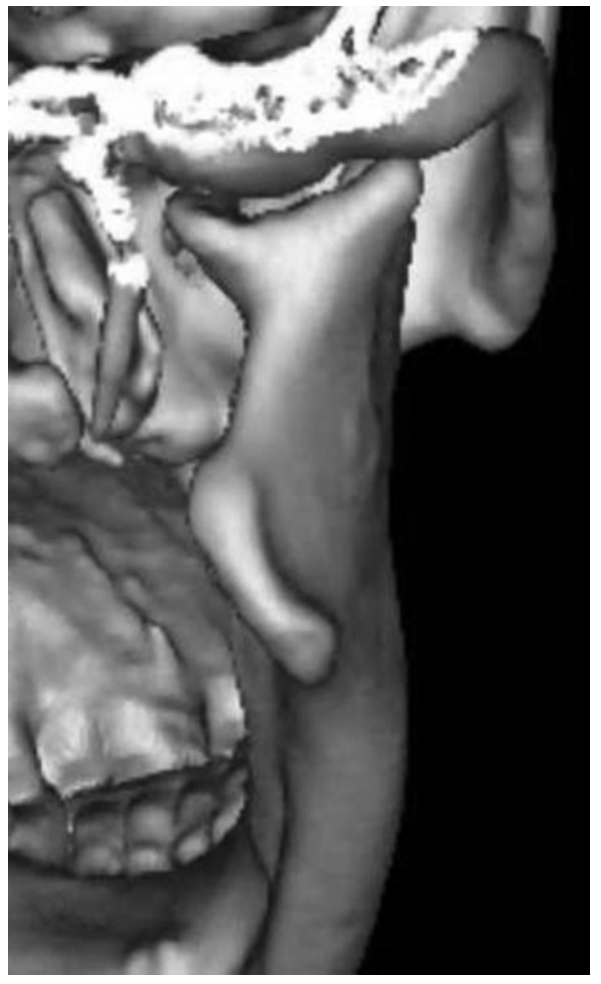

b

Figure 6 CT reconstruction images revealed the right temporal bone, condyle (a) and temporal fossa (b) 


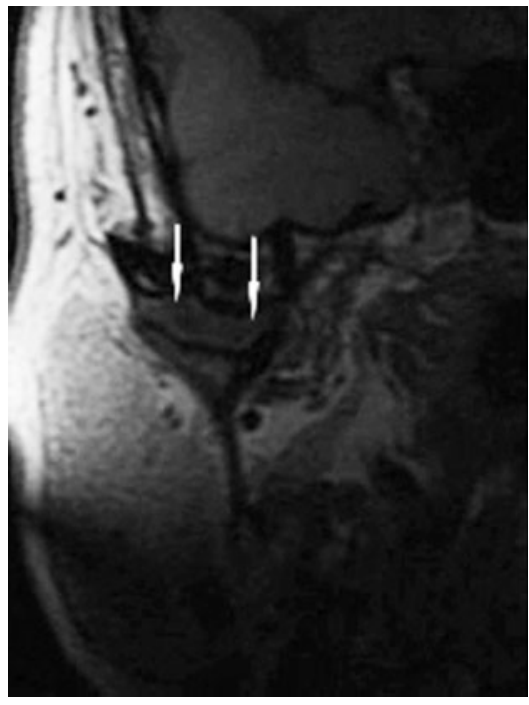

a

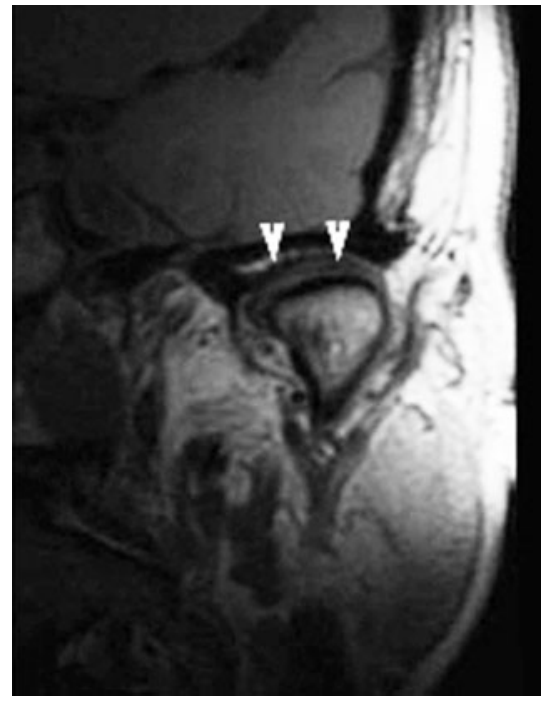

b

Figure 7 MRI ( $T_{1}$ weighted image, coronal view) revealed neither medial nor lateral disc displacement: (a) the right temporomandibular joint (TMJ) disc (arrows) and (b) the left TMJ disc (arrow heads)

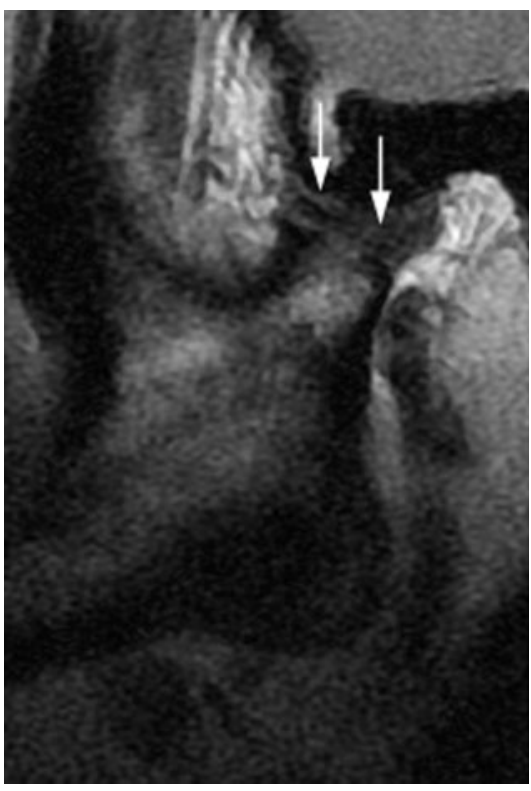

a

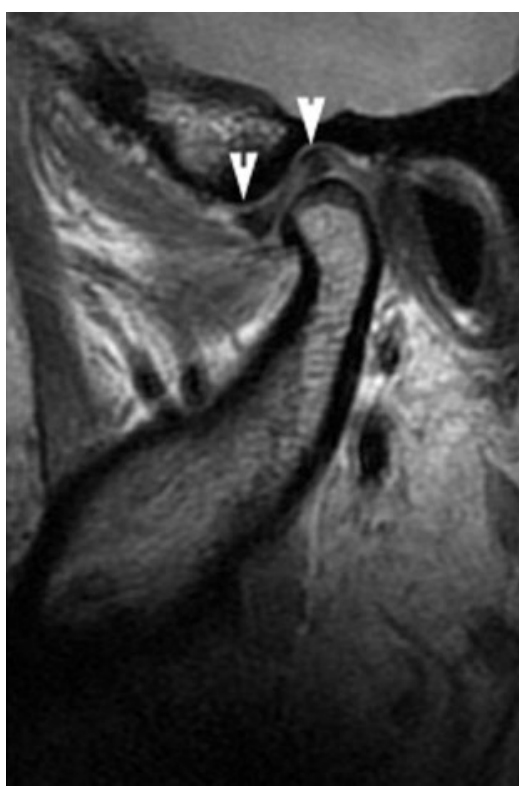

b

Figure 8 MRI ( $T_{1}$ weighted image, sagittal view, close-mouth position) revealed deformed articular disc was on the top of the hypoplastic right mandibular condyle (arrows). At the left side, form and position of the articular disc was normal (arrow heads): (a) the right temporomandibular joint (TMJ) and (b) the left TMJ

findings which revealed no disc displacement associated with the bifid heads. However, most of the previous studies did not exhibit MRI findings so we cannot compare exact features of the articular disc in patients with bifid or trifid mandibular condyles. MRI findings in this case indicate the right articular disc was malformed and it was located on the top of the condyle in either a closed-mouth or open-mouth position.
Morphological alterations regarding mandibular condyle may be encountered during routine examinations. Clinicians should be aware of these conditions and should apply advanced imaging modalities in order to avoid possible misleading interpretations. In general, therapy isn't necessary owing to a lack of clinical symptoms, but the clinicians may follow-up and inform the patients about this condylar variation. 


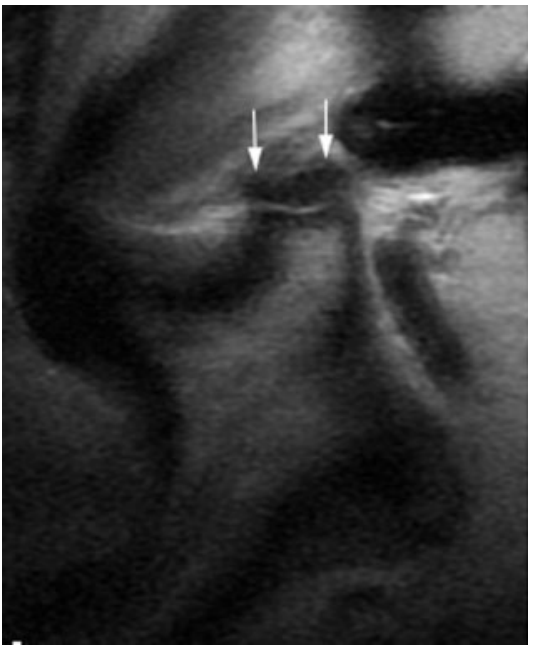

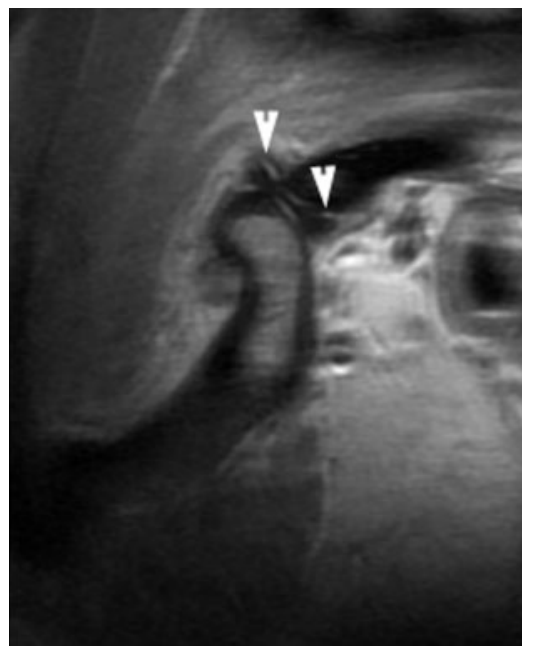

b

Figure 9 MRI (proton density-weighted image, sagittal view, open-mouth position) revealed that the right articular disc was in the same position as the closed-mouth state (arrows). The left articular disc was positioned posteriorly (arrow heads). (a) The right temporomandibular joint (TMJ) and (b) the left TMJ

\section{References}

1. Gundlach KK, Fuhrmann A, Beckmann-Van der Ven G. The double headed mandibular condyle. Oral Surg Oral Med Oral Pathol 1987; 64: 249-253.

2. Stadnicki G. Congenital double condyle of the mandible causing temporomandibular ankylosis: Report of a case. J Oral Surg 1971; 29: 208-211.

3. To EW. Mandibular ankylosis associated with a bifid condyle J Craniomaxillofac Surg 1989; 17: 326-328.

4. Daniels JS, Ali I. Post-traumatic bifid condyle associated with temporomandibular joint ankylosis: Report of a case and review of the literature. Oral Surg Oral Med Oral Pathol Oral Radiol Endod 2005; 99: 682-688.

5. Sales MA, Oliveira JX, Cavalcanti MG. Computed tomography imaging findings of simultaneous bifid mandibular condyle and temporomandibular joint ankylosis: Case report. Bras Dent J 2007; 18: 74-77.

6. Hersek N, Ozbek M, Tasar F, Akpinar E, Firat M. Bifid mandibular condyle: a case report. Dent Traumatol 2004; 20 : 184-186.

7. Mangenello-Souza LC, Mariani PB. Temporomandibular joint ankylosis: report of 14 cases. Int J Oral Maxillofac Surg 2003; 32: 24-29.

8. Schier MB. The temporomandibular joint. A consideration of its probable functional and dysfunctional sequelae and report: Condyle double head in a living person. Dent Item Interest 1948; 70: 889 .

9. Lysell L, Oberg T. Unilateral doubling of mandibular condyle. Dentomaxillofac Radiol 1975; 4: 95-98.

10. Formand M. Mandibular condylar head duplication. A case report. J Maxillofac Surg 1981; 9: 59-60.

11. Forman GH, Smith NJ. Bifid mandibular condyle. Oral Surg Oral Med Oral Pathol 1984; 57: 371-373.

12. Smith AC. Duplication of the condyle. Oral Surg Oral Med Oral Pathol 1985; 60: 456.

13. Balciunas BA. Bifid mandibular condyle. J Oral Maxillofac Surg 1986; 44: 324-325.

14. Thomason JM, Yusuf H. Traumatically induced bifid mandibular condyle: Report of two cases. Br Dent J 1986; 161: 291-293.

15. Quayle AA, Adams JE. Supplemental mandibular condyle. Br J Oral Maxillofac Surg 1986; 24: 349-356.

16. Shaber EP. Bilateral bifid mandibular condyles. Cranio 1987; 5: 191-195.
17. Zohar Y, Laurian N. Bifid condyle of the mandible associated with polythelia and manual anomalies. J Laryngol Otol 1987; 101: 1315-1319.

18. Sahm G, Witt E. Long-term results after childhood condylar fractures. A computed tomographic study. Eur J Orthod 1989; 11: $154-160$.

19. McCormick SU, McCormick SA, Graves RW, Pifer RG Bilateral bifid mandibular condyles. Report of three cases. Oral Surg Oral Med Oral Pathol 1989; 68: 555-557.

20. To EW. Supero-lateral dislocation of sagittally split bifid mandibular condyle. Br J Oral Maxillofac Surg 1989; 27: $107-113$.

21. Loh FC, Yeo JF. Bifid mandibular condyle. Oral Surg Oral Med Oral Pathol 1990; 69: 24-27.

22. Philips JD, Delzer DD. Unilateral bifid mandibular condyle. Gen Dent 1992; 40: 425.

23. Antoniades K, Karakasis D, Elephteriades J. Bifid mandibular condyle resulting from a sagittal fracture of the condylar head. Br J Oral Maxillofac Surg 1993; 31: 24-26.

24. Fields R, Frederiksen NL. Facial trauma confusing the diagnosis of a bifid condyle. Dentomaxillofac Radiol 1993; 22: 216-217.

25. Wu XG, Hong M, Sun KH. Severe osteoarthrosis after fracture of the mandibular condyle: a clinical and histologic study of seven patients. J Oral Maxillofac Surg 1994; 52: 138-142.

26. Kahl B, Fischbach R, Gerlach KL. Temporomandibular joint morphology in children after treatment of condylar fractures with functional appliance therapy: a follow-up study using computed tomography. Dentomaxillofac Radiol 1995; 24: 37-45.

27. Cowan DF, Ferguson MM. Bifid mandibular condyle. Dentomaxillofac Radiol 1997; 26: 70-73.

28. Stefanou EP, Fanourakis IG, Vlastos K, Katerelou J. Bilateral bifid mandibular condyles. Report of four cases. Dentomaxillofac Radiol 1998; 27: 186-188.

29. Garcia-Gonzalez D, Martin-Granizo R, Lopez P. Imaging quiz case 4. Bifid mandibular condyle. Arch Otolaryngol Head Neck Surg 2000; 126: 798-799.

30. Artvinli LB, Kansu O. Trifid mandibular condyle: a case report. Oral Surg Oral Med Oral Pathol Oral Radiol Endod 2003; 95: 251-254.

31. Antoniades K, Hadjipetrou L, Antoniades V, Paraskevopoulos K. Bilateral bifid mandibular condyle. Oral Surg Oral Med Oral Pathol Oral Radiol Endod 2004; 97: 535-538. 
32. De Sales MA, Amaral JI, Amorim RF, Almeida Freitas R. Bifid mandibular condyle: case report and etiological considerations. $J$ Can Dent Assoc 2004; 70: 158-162.

33. Hersek N, Ozbek M, Tasar F, Akpinar E, Firat M. Bifid mandibular condyle: a case report. Dent Traumatol 2004; 20: 184-186.

34. Alpaslan S, Ozbek M, Hersek N, Kanli A, Avcu N, Firat M. Bilateral bifid mandibular condyle. Dentomaxillofac Radiol 2004; 33: $274-277$.

35. Shriki J, Lev R, Wong BF, Sundine MJ, Hasso AN. Bifid mandibular condyle: $\mathrm{CT}$ and MR imaging appearance in two patients: case report and review of the literature. $A J N R$ Am J Neuroradiol 2005; 26: 1865-1868.

36. Corchero-Martin G, Gonzalez-Teran T, Garcia-Reija MF, Sanchez-Santolino S, Saiz-Bustillo R. Bifid condyle: case report. Med Oral Patol Oral Cir Bucal 2005; 10: 277-279.

37. Ramos FM, Filho JO, Manzi FR, Boscolo FN, Almeida SM. Bifid mandibular condyle: a case report. J Oral Sci 2006; 48 : 35-37.

38. Espinosa-Femenia M, Sartorres-Nieto M, Berini-Aytes L, GayEscoda C. Bilateral bifid mandibular condyle: case report and literature review. Cranio 2006; 24: 137-140.

39. Agarwal V, Suhas S, Pai KM, Shetty CM, Auluck A. Bifid mandibular condyles: report of four cases. Dent Update 2006; 33 : 368-370.

40. Acikgoz A. Bilateral bifid mandibular condyle: a case report. J Oral Rehabil 2006; 33: 784-787.

41. Tuncbilek G, Cavdar G, Mavili ME. Bifid mandibular condyle: a rare disorder. J Craniofac Surg 2006; 17: 1207-1209.

42. Menezes AV, de Moraes Ramos FM, de Vasconcelos-Filho JO, Kurita LM, de Almeida SM, Haiter-Neto F. The prevalence of bifid mandibular condyle detected in a Brazilian population. Dentomaxillofac Radiol 2008; 37: 220-223.
43. Plevnia JR, Smith JA, Stone CG. Bifid mandibular condyle withouth history of trauma or pain: Report of a case. J Oral Maxillofac Surg 2009; 67: 1555-1561.

44. Gulati A, Virmani V, Ramanathan S, Verma L, Khandelwal N. Bifid mandibular condyle with temporomandibular joint ankylosis: report of two cases and review of the literature. Skeletal Radiol 2009; 38: 1023-1025.

45. Rehman TA, Gibikote S, Ilango N, Thaj J, Sarawagi R, Gupta A. Bifid mandibular condyle with associated temporomandibular joint ankylosis: a computed tomography study of the patterns and morphological variations. Dentomaxillofac Radiol 2009; 38: 239-244.

46. Miloglu O, Yalcin E, Buyukkurt MC, Yilmaz AB, Harorli A. The frequency of bifid mandibular condyle in Turkish patient population. Dentomaxillofac Radiol 2010; 39: 42-46.

47. Cagirankaya LB, Hatipoglu MG. Trifid mandibular condyle: A case report. Cranio 2005; 23: 297-299.

48. Sezgin OS, Kayipmaz S. Trifid mandibular condyle: a case report. Oral Radiol 2009; 25: 146-148.

49. Hrdlicka A. Lower jaw: double condyles. Am J Phys Anthropol 1941; 28: 75-89.

50. Szenpetery A, Kocsis G, Maresik A. The problem of bifid mandibular condyle. J Oral Maxillofac Surg 1990; 48: 1254-1257.

51. Fonseca RJ. Arthritis of the temporomandibular joint. In: Fletcher J, Chappelle A (eds). Oral and maxillofacial surgery (1st edn). Philadelphia, PA: W.B. Saunders, 2000, pp 73-92.

52. White SC, Pharoah MJ. Malignant Diseases of the jaws. In: White SC, Pharoah MJ (eds). Oral Radiology Principles and Interpretation (5th edn). St Louis, MO: CV Mosby, 2000, pp 458-484.

53. White SC, Pharoah MJ. Specialized radiographic techniques. In: White SC, Pharoah MJ (eds). Oral radiology principles and interpretation (5th edn). St Louis, MO: CV Mosby, 2000, pp 255-260. 